\section{Accuracy of the clinical diagnosis of chalazion}

\section{Abstract \\ Purpose A chalazion, localized} lipogranulomatous inflammation of the eyelid, may simulate various eyelid lesions. This study was conducted to determine the accuracy of the clinical diagnosis of chalazion and demonstrate the importance of histopathological confirmation of the diagnosis.

Methods Histopathological diagnoses of 1060 cases with the clinical diagnosis of chalazion, submitted to the Henry C Witelson Ophthalmic Pathology Laboratory and Registry between September 1993 and December 2001, were retrospectively evaluated. Discrepancies between clinical and histopathological diagnoses were classified. Results A total of 1033 (97.4\%) of the 1060 cases were clinically diagnosed as primary and the remaining $27(2.6 \%)$ as recurrent chalazions. Agreement was noted between clinical and histopathological diagnoses in 992 (93.6\%) cases. Of the $68(6.4 \%)$ clinically misdiagnosed cases, $15(1.4 \%)$ were found to be malignant, two $(0.2 \%)$ premalignant, and 51 $\mathbf{( 4 . 8 \% )}$ benign conditions. Sebaceous cell carcinoma was the most commonly missed malignancy (12 cases, $1.1 \%$ ) followed by basal cell carcinoma (three cases, $0.3 \%$ ).

Premalignant lesions, which masqueraded as chalazion, were chronic inflammation with cellular atypia and mitotic figures (two cases, $0.2 \%)$. Of these 17 cases with premalignant and malignant histopathologies, only six (35.3\%) had a clinical diagnosis of recurrent chalazion, whereas the others $(64.7 \%)$ were primary cases. Of the various benign conditions that were misdiagnosed as chalazion, different types of chronic inflammation ( 24 cases, $2.2 \%$ ) were the most frequent.

Conclusions A number of different benign, premalignant, and malignant conditions may clinically masquerade as a chalazion. Delayed diagnosis and treatment of sebaceous cell carcinoma, which is the most frequently missed malignancy, may be life threatening
PÇ Özdal' ${ }^{1,2}$, F Codère ${ }^{2}$, S Callejo ${ }^{1}$, AL Caissie ${ }^{1}$ and MN Burnier ${ }^{1,2}$

for the patient. Therefore, all chalazion specimens, primary or recurrent, should be submitted for histopathological examination. Eye (2004) 18, 135-138. doi:10.1038/ sj.eye. 6700603

Keywords: chalazion; clinical diagnosis; accuracy; misdiagnosis; sebaceous cell carcinoma

\section{Introduction}

A chalazion is a localized lipogranulomatous inflammation that affects the sebaceous glands, particularly the meibomian glands of the eyelids. It usually arises secondary to noninfectious obstruction of sebaceous gland ducts. ${ }^{1,2}$ Previous studies have revealed that chalazion is the most common inflammatory lesion of the eyelid. ${ }^{3-6}$ Although they seem easy to clinically diagnose, chalazions can simulate a number of benign, premalignant, and malignant lesions. It is always important to remember that some malignant neoplasms, particularly sebaceous cell carcinoma (SebCC), can be misdiagnosed as chalazion. ${ }^{2,7-11}$ A limited number of single case reports ${ }^{8-12}$ or small series, ${ }^{13,14}$ discussing misdiagnosis of lesions masquerading as chalazion, have appeared in the literature. This present study was performed to determine the accuracy of the clinical diagnosis of chalazion and evaluate the importance of histopathological confirmation of the diagnosis in 1060 cases.

\section{Materials and methods}

The records of the histopathological diagnoses of 1067 clinically diagnosed chalazion cases, submitted to the Henry C Witelson Ophthalmic Pathology Laboratory and Registry between September 1993 and December 2001, were evaluated retrospectively. Seven cases with insufficient specimen for histopathological diagnosis were excluded from the study. Specimens were sent by different
${ }^{1}$ The Henry C Witelson Ophthalmic Pathology Laboratory and Registry McGill University Health Center Montréal, PQ Canada

${ }^{2}$ Department of Ophthalmology McGill University Health Center Montréal, PQ, Canada

Correspondence: PÇ Özdal

2050 de Maisonneuve Blvd W Apt\#902 H3H 1K7 Montreal, PQ

Canada

Tel: + 5149390122

Fax: + 5143985728

E-mail: pinarozdal@

hotmail.com

Received: 1 October 2002 Accepted in revised form: 26 March 2003

Presented at ARVO Annual Meeting, 5-10 May 2002 Ft Lauderdale

Authors have not received any public or private support in the preparation of the paper

This paper does not serve the financial or proprietary interests of any individuals or institutions 
ophthalmologists practising in the McGill University Health Center and included every case of chalazion seen in the hospital during the study period. Discrepancies between clinical and histopathological diagnoses were noted and classified.

\section{Results}

A total of 1033 of the 1060 cases (97.5\%) were clinically diagnosed as primary and the remaining $27(2.6 \%)$ cases as recurrent chalazions. Agreement was noted between clinical and histopathological diagnoses in 992 (93.6\%) cases (Figure 1a). Of the $68(6.4 \%)$ clinically misdiagnosed cases, $15(1.4 \%)$ were found to be malignant, two $(0.2 \%)$ premalignant, and $51(4.8 \%)$ benign conditions.

SebCC was the most commonly missed malignancy (12 cases, $1.1 \%$ ) (Figure 1b) followed by basal cell carcinoma (BCC) (three cases, $0.3 \%$ ) (Table 1). SebCC represented $80 \%$ and BCC represented $20 \%$ of the misdiagnosed malignant cases. Premalignant lesions, which masqueraded as chalazion, were chronic inflammation with cellular atypia and mitotic figures (two cases, $0.2 \%$ )
(Table 1). Examination of the medical records of these 17 cases with premalignant and malignant histopathologies revealed that only six (35.3\%) had a clinical diagnosis of recurrent chalazion, of which two were atypical (one had ulceration on third occurrence, other had bleeding in second occurrence). The remaining $64.7 \%$ were primary cases, diagnosed as chalazion without any doubt. Ages of these 17 cases ranged from 27 to 73 years with a mean of $56.4 \pm 13.8$ years.

Benign conditions, which were misdiagnosed as chalazion included different types of chronic inflammation (24 cases, 2.2\%), seborrheic keratosis (four cases, $0.4 \%$ ), epithelial inclusion cyst (four cases, $0.4 \%$ ), pyogenic granuloma (four cases, $0.4 \%$ ) (Figure 1c), papilloma (three cases, $0.3 \%$ ) (Figure 1d), sebaceous gland hyperplasia (three cases, $0.3 \%$ ), intradermal nevus (three cases, $0.3 \%$ ), inflammatory granulomatous foreign body reaction (three cases, $0.3 \%$ ), necrotizing granuloma (one case, $0.1 \%$ ), dermatofibroma (one case, $0.1 \%$ ), and hydrocystoma (one case, $0.1 \%$ ) (Table 2). Thus the different types of chronic inflammation were the most commonly misdiagnosed benign lesions.
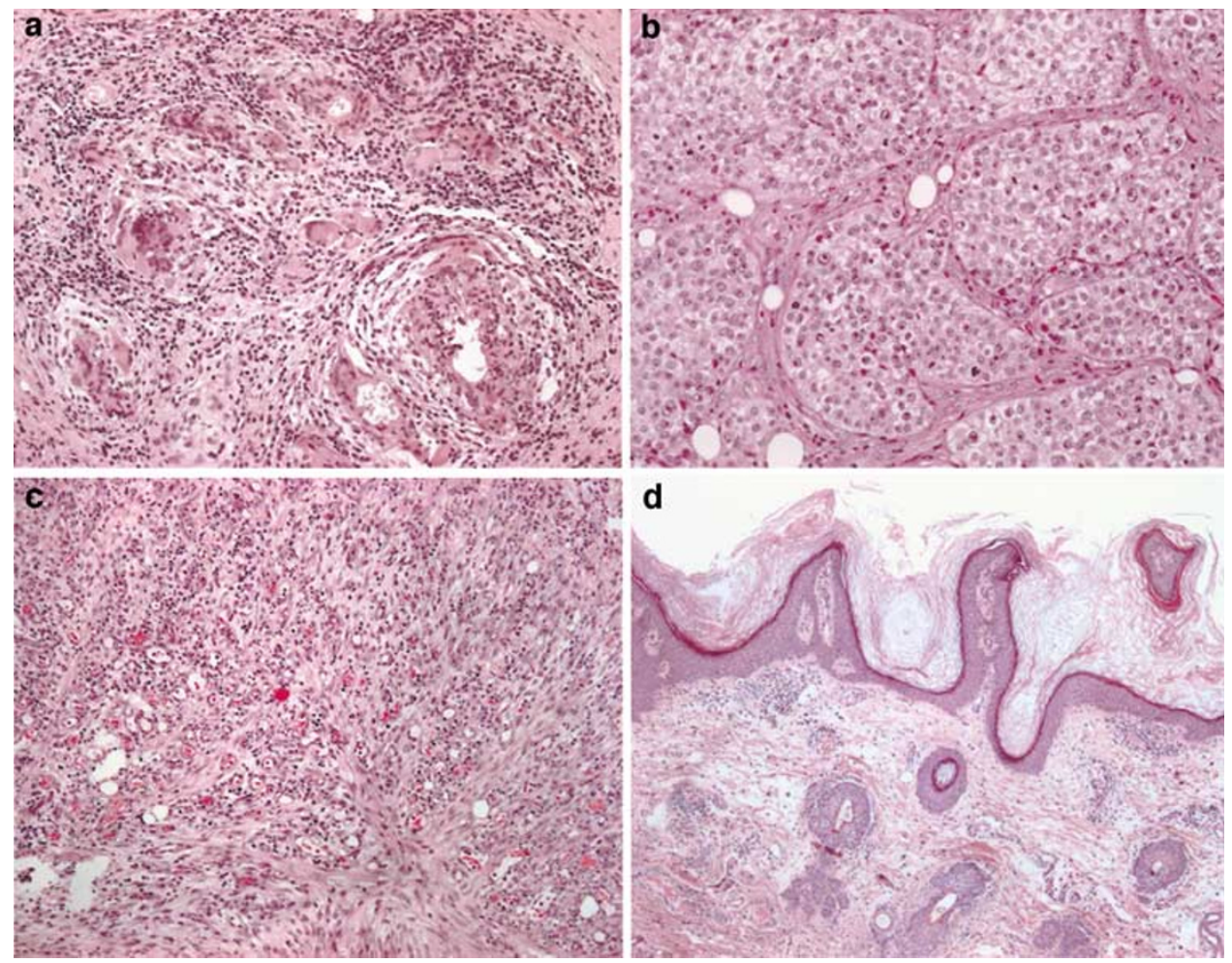

Figure 1 (a) Chalazion. Lipogranulomatous reaction containing epithelioid cells and multinucleated giant cells intermixed with lymphocytes and plasma cells (haematoxylin-eosin, $\times 200$ ). (b) Sebaceous cell carcinoma. Well-differentiated sebaceous cell carcinoma arranged in lobules containing cells with abundant pale and foamy cytoplasm. Few mitotic figures are seen (haematoxylin-eosin, $\times 400$ ) (c) Pyogenic granuloma. Granulation tissue composed of vascular channels, acute and chronic inflammatory cells infiltrating a loose stroma (haematoxylin-eosin, $\times 200$ ). (d) Squamous cell papilloma. Exhibition of finger-like projections of vascularized connective tissue covered by acanthotic epithelium with hyperkeratosis (haematoxylin-eosin, $\times 50$ ). 
Table 1 Malignant and premalignant eyelid lesions clinically misdiagnosed as chalazion

\begin{tabular}{lcc}
\hline Histopathological diagnosis & Number of cases & $\%$ \\
\hline Sebaceous cell carcinoma & 12 & 1.1 \\
Basal cell carcinoma & 3 & 0.3 \\
Chronic inflammation with cellular & 2 & 0.2 \\
atypia and mitotic figures & & \\
Total & 17 & 1.6 \\
\hline
\end{tabular}

Table 2 Benign eyelid lesions clinically misdiagnosed as chalazion

\begin{tabular}{lcc}
\hline Histopathological diagnosis & Number of cases & $\%$ \\
\hline Different types of chronic inflammation & 24 & 2.2 \\
Seborrheic keratosis & 4 & 0.4 \\
Epithelial inclusion cyst & 4 & 0.4 \\
Pyogenic granuloma & 4 & 0.4 \\
Papilloma & 3 & 0.3 \\
Sebaceous gland hyperplasia & 3 & 0.3 \\
Intradermal nevus & 3 & 0.3 \\
Inflammatory granulomatous foreign & 3 & 0.3 \\
body reaction & & \\
Necrotizing granuloma & 1 & 0.1 \\
Dermatofibroma & 1 & 0.1 \\
Hydrocystoma & 1 & 0.1 \\
& & \\
Total & 51 & 4.8 \\
\hline
\end{tabular}

\section{Discussion}

Owing to the diversity of tissues that are present, many types of benign and malignant tumours can occur in the eyelids. ${ }^{15}$ It is obvious that with a wide variety of eyelid lesions, clinical misdiagnosis cannot be completely avoided. Studies on the accuracy of the clinical diagnosis of eyelid lesions have revealed that clinical judgment could not provide $100 \%$ confidence. Of the clinically diagnosed benign lesions, $2 \%$ were found to be malignant upon histopathological evaluation by Kersten et al. ${ }^{16}$ They suggested histopathological evaluation in all lesions, no matter how apparently benign they are. In another study, a discrepancy between clinical and histopathological diagnoses was noted in $16.2 \%$ of the eyelid lesions; $4.6 \%$ of these were clinically presumed benign conditions later proven to be malignant. ${ }^{17}$

A chalazion is a benign inflammatory eyelid lesion, which shows slow and painless evolution. ${ }^{1}$ The fact that it may clinically masquerade SebCC, an invasive malignant tumour of the eyelid, makes its histopathological diagnosis very important. Apart from SebCC, ${ }^{7,8}$ various eyelid tumours such as Merkel cell tumour, ${ }^{9}$ desmoplastic malignant melanoma, ${ }^{10}$ microcystic adnexal carcinoma, ${ }^{11}$ and neurilemoma ${ }^{12}$ have already been reported masquerading as chalazion.
Histopathological examination of a chalazion shows a lipogranulomatous reaction caused by liberated lipid. A connective tissue pseudocapsule is often present around the lesion. Chalazion may resemble the granulomas seen in tuberculosis, sarcoidosis, and cat-scratch disease. ${ }^{1,2}$

Discrepancies between clinical and pathological diagnoses were found in $68(6.4 \%)$ of our 1060 cases. In previous two studies, the clinical misdiagnosis rate was reported to be 33 out of 138 cases $(23.9 \%)^{13}$ and 21 out of 89 cases $(23.6 \%) .{ }^{14}$ Benign eyelid lesions confused with chalazion accounted for $4.8 \%$ of all our cases. This rate was reported as being $16.6 \%$ by Domarus et $a l^{13}$ and $14.6 \%$ by Hollwich et al. ${ }^{14}$ In our study, 17 cases (1.6\%) misdiagnosed as chalazion had either malignant or premalignant histopathological diagnoses. This rate was $7.2^{13}$ and $9.1 \%^{14}$ in the two previous series mentioned above. In our clinic, even if there is no suspicion of the clinical diagnosis, all chalazion specimens are submitted for histopathological examination. This fact, along with the large number of cases included in our study, may explain the difference between our results and those of the previous studies.

Of the 15 missed malignant lesions, SebCC was the most common with 12 cases (80\%), followed by BCC with three cases (20\%). SebCC constituted $1.1 \%$ of all clinically diagnosed chalazion cases. Prognosis of this tumour is still regarded as being poor compared with most other malignant eyelid tumours, with a mortality rate second only to malignant melanoma. ${ }^{7}$ The poor prognosis of SebCC is closely associated with its ability to masquerade as other benign or less invasive conditions, resulting in delayed diagnosis and treatment. A review of 40 SebCC cases revealed that eight cases $(20 \%)$ appeared as recurrent chalazions. ${ }^{18}$ Besides chalazion, SebCC can present as other clinical entities such as blepharitis, blepharoconjunctivitis, meibomitis, superior limbic keratokonjunctivitis, and BCC. $7,15,19$ Thus the histopathological evaluation of these conditions is very important in the early diagnosis and treatment of SebCC. Factors associated with worse prognosis of SebCC other than misdiagnosis, such as tumour size $\geqslant 10 \mathrm{~mm}$, duration of symptoms for more than 6 months as well as invasion of lymphatic channels, vascular structures, and the orbit, also prove the importance of early diagnosis. ${ }^{15}$

Histopathological examination of chalazion specimens is generally recommended in cases with atypical symptomatology, recurrence, high patient age, unilateral therapy-resistant keratoconjunctivitis, and regional lymph node involvement. ${ }^{13}$ Zurcher et $a l^{7}$ emphasized the importance of biopsy in uncertain and suspicious inflammatory conditions that fail to respond to appropriate treatment as well as in all suspicious chalazions. In a case report of SebCC masquerading as a rapidly recurring chalazion, the importance of complete 
surgical excision followed by histopathological examination in atypical eyelid lesions was stressed. ${ }^{8}$ Since SebCC usually presents as a small firm nodule resembling chalazion ${ }^{15}$ and $64.7 \%$ of the premalignant and malignant lesions misdiagnosed as chalazion were primary cases, we recommend submitting all chalazion specimens for histopathological confirmation. The cost of one histopathological examination is approximately 60 Canadian dollars (CAD). Evaluation of 1060 chalazion cases represented a cost of 63600 CAD. Thus the unsuspected 17 malignant and premalignant lesions were discovered at a cost of 3741 CAD per lesion (63600/ 17). This amount is much less than the cost of an exenteration (costs around $6000 \mathrm{CAD}$ ) and/or other treatment modalities for one metastatic SebCC patient. Beyond this, we all know that delayed diagnosis and treatment of SebCC may threaten the patient's life. Therefore, submission of all chalazion samples for histopathological evaluation is the most cost-effective and safest approach to avoid missing malignancies, particularly SebCC.

\section{References}

1 Font RL. Eyelids and lacrimal drainage system. In: Spencer WH (ed). Ophthalmic Pathology Vol 4. WB Saunders: Philadelphia, PA, 1996; p 2355.

2 Shields JA, Shields CL (eds). Atlas of eyelid and conjunctival tumors. Williams \& Wilkins: Philadelphia, PA, 1999, pp 164-165.

3 Welch RB, Duke JR. Lesions of the lids: a statistical note. Am J Ophthalmol 1958; 45: 415-416.

4 Aurora AL, Blodi FC. Lesions of the eyelids: a clinicopathological study. Surv Ophthalmol 1970; 15: 94-104.

5 Scat Y, Liotet S, Carre F. Epidemiological study of benign tumors and inflammatory pseudotumors of the eye and its adnexa. J Fr Ophthalmol 1996; 19: 514-519.
6 Tesluk GC. Eyelid lesions: incidence and comparison of benign and malignant lesions. Ann Ophthalmol 1985; 17: 704-707.

7 Zurcher M, Hintschich CR, Garner A, Bunce C, Collin JRO. Sebaceous carcinoma of the eyelid: a clinicopathological study. Br J Ophthalmol 1998; 82: 1049-1055.

8 Gerber DM, Meyer P, Messerli JO, Piffaretti JM, Haefliger IO. Masquerade of sebaceous gland carcinoma as a rapidly recurring 'chalazion', a case report. Klin Monatsbl Augenheilkd 2001; 218: 391-393.

9 Whyte IF, Orrell JM, Roxburgh ST. Merkell cell tumor of the eyelid masquerading as a chalazion. J $R$ Coll Surg Edinburgh 1991; 36: 129-130.

10 Roper JP, Jones T, Common JD. Desmoplastic malignant melanoma masquerading as a chalazion. Br J Ophthalmol 1986; 70: 907-910.

11 Brookes JL, Bentley C, Verma S, Olver JM, McKee PH. Mycrocystic adnexal carcinoma masquerading as a chalazion. Br J Ophthalmol 1998; 82: 196-200.

12 Shields JA, Guibor P. Neurilemoma of the eyelid resembling a recurrent chalazion. Arch Ophthalmol 1984; 102: 1650 .

13 Domarus DV, Hinzpeter EN, Naumann GOH. The clinical misdiagnosis of chalazion. Klin Monatsbl Augenheilkd 1976; 168: $175-181$.

14 Hollwich F, Schiffer HP, Busse H. Misdiagnosis of 'chalazion'. Klin Monatsbl Augenheilkd 1976; 168: 591-594.

15 Mc Lean IW, Burnier MN, Zimmerman LE, Jacobiec FA. Tumors of the eyelid. In: Rosai J, Sobin LH (eds). Atlas of Tumor Pathology. Tumors of the Eye and Ocular Adnexa. Armed Forces Institute of Pathology: Washington, DC, 1994, pp 28-35.

16 Kersten RC, Ewing-Chow D, Kulwin DR, Gallon M. Accuracy of clinical diagnosis of cutaneous eyelid lesions. Ophthalmology 1997; 104: 479-464.

17 Margo CE. Eyelid tumors: accuracy of clinical diagnosis. Am J Ophthalmol 1999; 128: 635-636.

18 Doxanas MT, Green WR. Sebaceous gland carcinoma. Review of 40 cases. Arch Ophthalmol 1984; 102: 245-249.

19 Kass LG, Hornblass A. Sebaceous carcinoma of the ocular adnexa. Surv Ophthalmol 1989; 33: 477-490. 